\title{
Serum Levels of $\alpha$-Klotho Are Correlated with Cerebrospinal Fluid Levels and Predict Measures of Cognitive Function
}

\author{
Payel Kundu ${ }^{\mathrm{a}}$, Benjamin Zimmerman ${ }^{\mathrm{a}, \mathrm{b}, \mathrm{c}}$, Joseph F. Quinn ${ }^{\mathrm{d}, \mathrm{e}}$, Jeffrey Kaye ${ }^{\mathrm{d}}$, Nora Mattek ${ }^{\mathrm{d}}$, \\ Shawn K. Westaway ${ }^{\mathrm{d}}$ and Jacob Raber ${ }^{\mathrm{a}, \mathrm{d}, \mathrm{f}, *}$ \\ ${ }^{a}$ Department of Behavioral Neuroscience, Oregon Health and Science University, Portland, OR, USA \\ ${ }^{\mathrm{b}}$ Advanced Imaging Research Center, Oregon Health and Science University, Portland, OR, USA \\ ${ }^{\mathrm{c}}$ Beckman Institute for Advanced Science and Technology, University of Illinois at Urbana-Champaign, Urbana, \\ IL, USA \\ ${ }^{\mathrm{d}}$ Department of Neurology, Oregon Health and Science University, Portland, OR, USA \\ ${ }^{\mathrm{e}}$ Department of Neurology, Veterans Affairs Medical Center, Portland, OR, USA \\ ${ }^{\mathrm{f}}$ Departments of Psychiatry and Radiation Medicine, Division of Neuroscience, ONPRC, Oregon Health and \\ Science University, Portland, OR, USA
}

Accepted 18 January 2022

Pre-press 21 February 2022

\begin{abstract}
.
Background: $\alpha$-klotho might play a role in neurodegenerative diseases.

Objective: To determine levels of $\alpha$-klotho and apoE in serum and cerebrospinal fluid (CSF) samples and their relationship with the Mini-Mental State Examination (MMSE) and Clinical Dementia Rating (CDR).

Methods: All subjects were between age 39 to $83+(n=94)$. CDR and MMSE were administered to all participants. CSF was collected in the early afternoon by lumbar puncture.

Results: Serum and CSF levels of $\alpha$-klotho are positively correlated and both predict scores on the MMSE and CDR, regardless of sex or apoE4 status.

Conclusion: Our results demonstrate that $\alpha$-klotho may be an important biomarker of cognitive health and neurodegeneration, and that relatively non-invasive sampling of $\alpha$-klotho from serum is likely highly reflective of CSF levels.
\end{abstract}

Keywords: $\alpha$-klotho, apoE, cerebrospinal fluid, Clinical Dementia Rating, Mini-Mental State Examination, serum

\section{INTRODUCTION}

$\alpha$-klotho levels are high in the cerebrospinal fluid (CSF) [1-3] and related to insulin signaling, cognition, and lifespan in mice [1, 3-6]. Mouse and human $\alpha$-klotho share $80 \%$ homology [7]. Heterozygote carriers of the KL-VS $\alpha$-klotho variant have higher $\alpha$-klotho serum levels $[6,8]$ and show better global cognition [6].

\footnotetext{
${ }^{*}$ Correspondence to: Jacob Raber, Department of Behavioral Neuroscience, L470, Oregon Health \& Science University, 3181SW Sam Jackson Park Road, Portland, OR 97239, USA. E-mail: raberj@ohsu.edu.
}

Apolipoprotein E (apoE) plays a role in cholesterol metabolism. In humans, there are three major isoforms. Compared to apoE3, apoE4 increases and apoE2 decreases the risk of developing Alzheimer's disease (AD) [9, 10]. Carrying one copy of the KL-VS $\alpha$-klotho variant predicted better cognitive outcomes [6] and was also associated with a larger right dorsolateral prefrontal cortex volume [11]. In healthy older adults, higher serum $\alpha$-klotho levels were associated with greater intrinsic connectivity within the frontoparietal network, the default mode network, and other functional networks vulnerable to AD-related cognitive decline [8]. $\alpha$-klotho protein levels in the CSF 
Table 1

A demographic table of participant information

\begin{tabular}{|c|c|c|c|}
\hline Category & Sub-category & Frequency $(\mathrm{N})$ & Percent $(\%)$ \\
\hline \multirow[t]{2}{*}{ Sex } & Female & 45 & 48 \\
\hline & Male & 49 & 52 \\
\hline \multirow{3}{*}{$\begin{array}{l}\text { Years of } \\
\text { education }\end{array}$} & 8-12 (High School) & 30 & 32 \\
\hline & $13-16($ College $)$ & 40 & 43 \\
\hline & 18-21 (Graduate school) & 23 & 25 \\
\hline \multirow[t]{2}{*}{ Race } & Caucasian & 93 & 99 \\
\hline & Black & 1 & 1 \\
\hline \multirow{5}{*}{$\begin{array}{l}\text { Age at sample } \\
\text { collection }\end{array}$} & $39-49$ & 6 & 6 \\
\hline & $50-60$ & 23 & 25 \\
\hline & $61-71$ & 34 & 37 \\
\hline & $72-82$ & 26 & 28 \\
\hline & $83+$ & 4 & 4 \\
\hline \multirow[t]{5}{*}{$A P O E$ genotype } & $\mathrm{E} 2 / \mathrm{E} 3$ & 5 & 6 \\
\hline & $\mathrm{E} 2 / \mathrm{E} 4$ & 4 & 5 \\
\hline & E3/E3 & 33 & 39 \\
\hline & $\mathrm{E} 3 / \mathrm{E} 4$ & 33 & 39 \\
\hline & $\mathrm{E} 4 / \mathrm{E} 4$ & 10 & 12 \\
\hline \multirow{10}{*}{$\begin{array}{l}\text { Diagnosis at } \\
\text { sample collection }\end{array}$} & Familial AD control - at risk & 3 & 3 \\
\hline & Frontotemporal dementia & 1 & 1 \\
\hline & Mixed dementia & 1 & 1 \\
\hline & Normal - worried well & 1 & 1 \\
\hline & Not demented & 40 & 43 \\
\hline & Other dementia & 1 & 1 \\
\hline & Other disease without dementia & 2 & 2 \\
\hline & Possible Alzheimer's disease - other complications & 6 & 6 \\
\hline & Probable Alzheimer's disease & 29 & 31 \\
\hline & Questionable dementia & 10 & 11 \\
\hline
\end{tabular}

are lower in women than men, lower in older adults with $\mathrm{AD}$ than age-matched controls, and decline with age [3]. Homozygous apoE4 carriers have lower brain levels of apoE in the hippocampus, frontal cortex and CSF compared to homozygous apoE3 and apoE2 carriers [12-14]. High $\alpha$-klotho levels may especially benefit apoE4 carriers $[15,16]$.

Recently, we reported a robust positive relationship between $\alpha$-klotho and apoE levels in the amygdala in irradiated non-human primates [17]. In the present study, we determined human serum and CSF $\alpha$-klotho and apoE levels to investigate whether serum levels are related to CSF levels and whether either measure is related to cognitive health and whether this depends on apoE4 status.

\section{MATERIAL AND METHODS}

\section{Subjects}

This is a cross-sectional observational study of banked specimens from cerebrospinal fluid donors at a single NIA-funded ADcenter. All subjects with a banked CSF sample, regardless of diagnosis, were included. All subjects for whom we analyzed CSF and serum samples were seen at the Ore- gon Alzheimer's Disease Center between age 39 to $83+(n=94)$. Table 1 contains the demographic information of the participants. The data presented represent the clinical evaluation closest in time to sample collection. The dates of the sample collection was between May 30, 1996 and October 6, 2008. Diagnosis of probable AD was made in each case accord of volunteers. The Oregon Aging and Alzheimer's Disease Center enrolls clinic patients and community volunteers in natural history studies and collects a battery of data as prescribed by the National Alzheimer's Coordinating Center (NACC), including demographic information, MiniMental State Examination (MMSE), etc. Diagnosis is made at a consensus conference involving neurologists, psychiatrists, neuropsychologists, and other clinical staff. CSF is collected on a sub-population according to NINDS-ADRDA criteria [20]. Subjects were nonsmokers, in good general health, and free of past or present major psychiatric or neurological disorders (other than AD). Clinical Dementia Rating (CDR) and MMSE were administered to all participants as described [20]. CSF was collected in the early afternoon by lumbar puncture, and specimens were kept frozen at $-70^{\circ} \mathrm{C}$ until the assay. $A P O E$ genotype was known for all these subjects as part of 
the Alzheimer's Disease Center database at OHSU. The experimenter performing the apoE and $\alpha$-klotho ELISAs was blinded to the APOE genotype and cognitive status until all of the data were analyzed. This study was approved by the Oregon Health and Science University Institutional Review Board ("Layton Aging And Alzheimer's Disease Center Research Repository Protocol", IRB \#6845). All participants provided written informed consent.

\section{Quantification of $\alpha$-klotho and apoE}

Protein levels of $\alpha$-klotho and apoE were quantified in serum and CSF samples collected from human subjects using commercial ELISA-based quantification assays (IBL America, Minneapolis, MN, USA and MilliporeSigma, Darmstadt, Germany, respectively), according to the manufacturer's instructions. Briefly, test dilutions were first used to ensure that $\alpha$ klotho and apoE levels fell within the standard curve range. At the end of the assay, absorbances were read at $450 \mathrm{~nm}$ using an ID5reader (Molecular Devices, San Jose, CA). The $\alpha$-klotho ELISA kit stated an intra-assay CV value of $3.1 \%$ and an inter-assay CV value of $2.9 \%$. The apoE ELISA kit stated an intraassay CV value of less than $10 \%$, and an inter-assay $\mathrm{CV}$ value of less than $12 \%$.

\section{Statistical analyses}

Pearson's correlation analyses were used to investigate the relationships between variables. Where appropriate, ANOVA tests were used to investigate differences between groups. Statistical significance was determined using an error probability level of $p<0.05$. Where appropriate, Tukey's post hoc tests were conducted for pairwise comparisons. Data were analyzed using SPSS Statistics for Windows (Version 25, Armonk, NY: IBM Corp., Chicago, IL, USA), and figures were generated using Graphpad Prism software (San Diego, CA, USA).

\section{RESULTS}

\section{CSF and serum $\alpha$-klotho levels are highly correlated}

Serum and CSF protein levels of $\alpha$-klotho were highly positively correlated $(\mathrm{r}(92)=0.572$, $p<0.001)$ (Fig. 1A). This relationship was also seen when males and females were analyzed separately (males: $\mathrm{r}(47)=0.479, p=0.001$ (Fig. 1B); females: $\mathrm{r}(43)=0.714, p<0.001$ (Fig. 1C).

\section{Levels of $\alpha$-klotho correlate with cognitive status}

Protein levels of $\alpha$-klotho were strongly positively correlated with MMSE scores in both serum $(\mathrm{r}(91)=0.348, p=0.001)$ (Fig. $2 \mathrm{~A})$ and CSF $(\mathrm{r}(91)=0.457, p<0.001)$ (Fig. 2B). The relationship between serum $\alpha$-klotho and MMSE scores was seen in both apoE4 carriers $(\mathrm{r}(44)=0.377$, $p=0.010)$ and non-carriers $(\mathrm{r}(36)=0.337, p=0.038)$ (Fig. 2C). Similarly, there was a relationship between CSF $\alpha$-klotho and MMSE scores in both apoE4 carriers $(\mathrm{r}(44)=0.452, p=0.002)$ and non-carriers $(\mathrm{r}(37)=0.554, p<0.001) \quad($ Fig. 2D). Of the 93 participants with MMSE scores, 29 participants achieved the maximum score of 30 points. Thus, to ensure that our results were not confounded by the presence of a ceiling effect in the data, another analysis was conducted in which all values corresponding to the maximum MMSE score were excluded. Protein levels of $\alpha$-klotho in both the serum $(\mathrm{r}(62)=0.367, p=0.003)($ Fig. $2 \mathrm{E})$ and CSF, $(\mathrm{r}(62)=0.340, p<0.006)($ Fig. $2 \mathrm{~F})$ were still strongly positively correlated with MMSE scores.
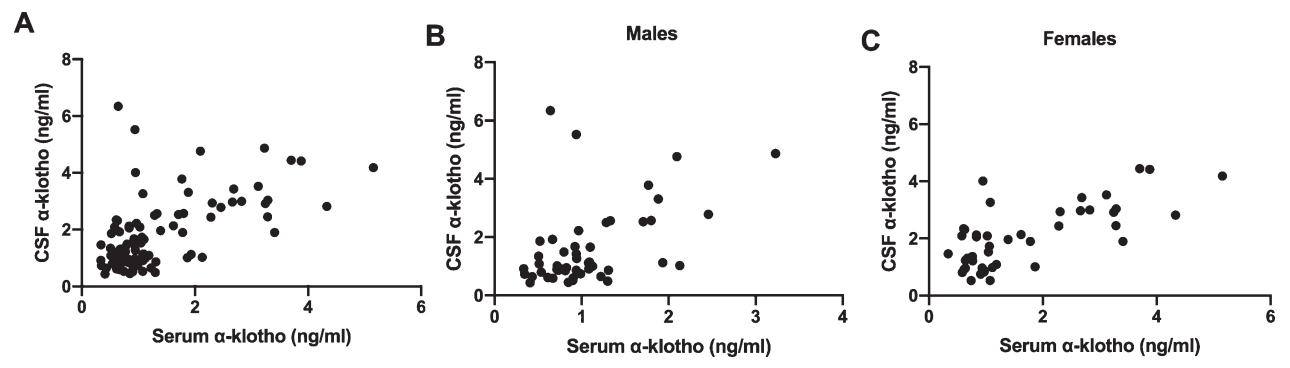

Fig. 1. A) There was a strong association between $\alpha$-klotho levels in the serum and the CSF. This was seen in males (B) and females (C). 
A

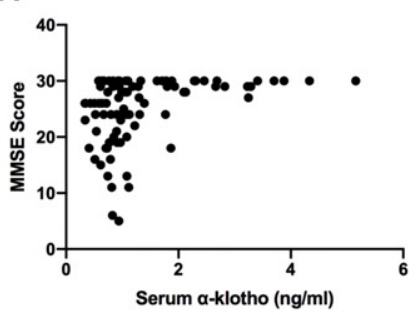

C

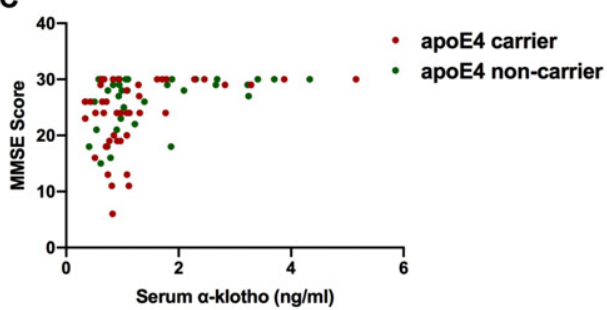

E

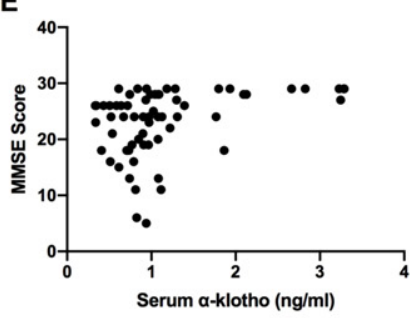

G

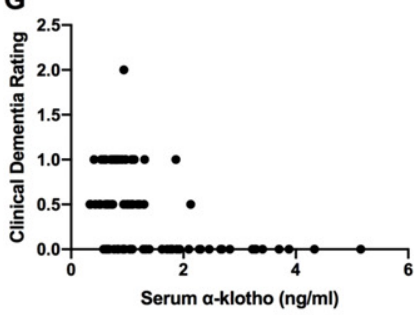

I

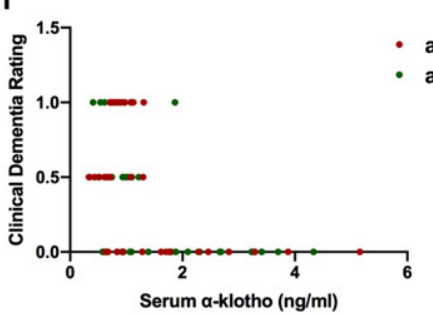

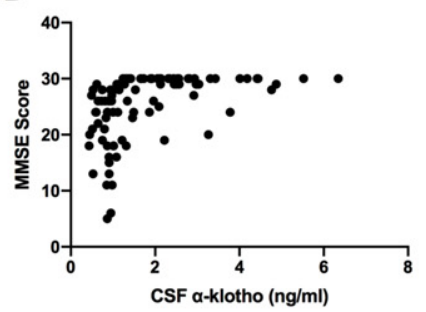

D

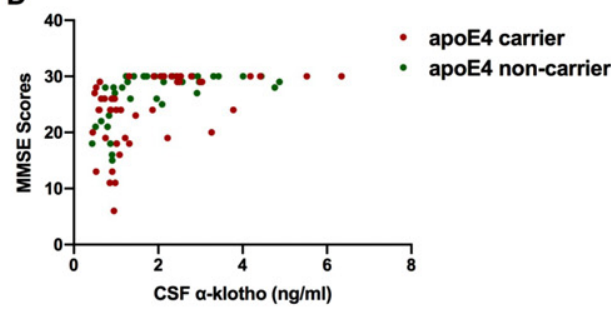

F

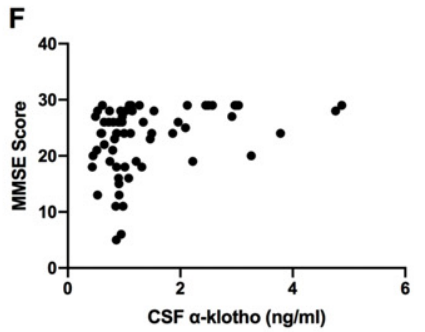

H

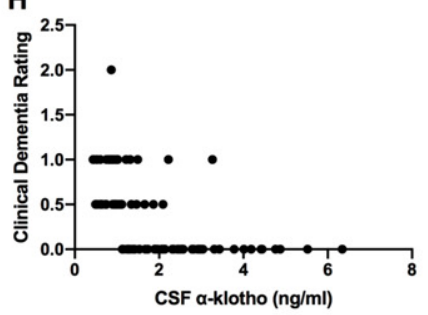

$\mathbf{J}$

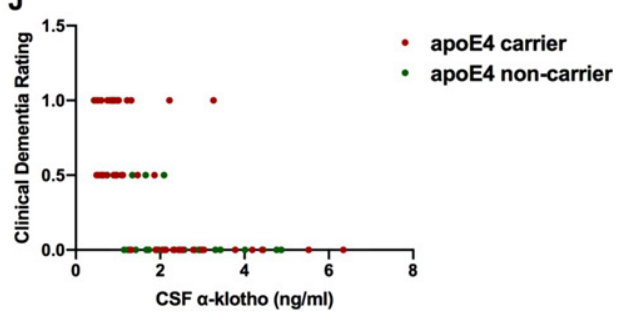

Fig. 2. $\alpha$-klotho levels in serum (A) and CSF (B) were strongly positively correlated with MMSE scores. The relationship between serum $\alpha$-klotho levels and MMSE scores was seen in both apoE4 carriers and non-carriers (C). Similarly, the relationship between CSF $\alpha$-klotho levels and MMSE scores held in apoE4 carriers and non-carriers (D). When maximum MMSE scores are excluded, $\alpha$-klotho levels in serum (E) and CSF (F) were still strongly positively correlated with MMSE scores. $\alpha$-klotho levels in serum (G) and CSF (H) were strongly negatively correlated with clinical dementia rating. This relationship was seen in both apoE4 carriers (I and J).

Protein levels of $\alpha$-klotho in both serum $(\mathrm{r}(91)=0.441, p<0.001$ and $\operatorname{CSF}(\mathrm{r}(91)=-0.600$, $p<0.001)$ were strongly negatively correlated with clinical dementia ratings (Figs. $2 \mathrm{G}$ and $2 \mathrm{H}$ respectively). This relationship was seen in both apoE4 carriers and non-carriers (Figs. 2I and 2J). In 
apoE4 carriers, serum $(\mathrm{r}(44)=-0.488, p=0.001)$ and CSF $(\mathrm{r}(44)=-0.628, p<0.001) \alpha$-klotho levels were negatively correlated with clinical dementia ratings. Similarly, in apoE4 non-carriers, serum $(\mathrm{r}(36)=-0.426, p=0.008)$ and $\operatorname{CSF}(\mathrm{r}(36)=-0.657$, $p<0.001) \alpha$-klotho were negatively correlated with CDR. In addition to CDR, we also analyzed the sum of boxes score, as previously described [21]. The sum of boxes scores and CDR were highly positively correlated $(\mathrm{r}(90)=0.944, p<0.001)$.

As expected, MMSE scores and the CDR were strongly negatively correlated $(\mathrm{r}(91)=-0.843$, $p<0.001$ ). Also as expected, years of education predicted MMSE scores $(\mathrm{r}(90)=0.260, p=0.012)$ and CDR $(\mathrm{r}(90)=-0.209, p=0.046)$.

\section{Sex differences in $\alpha$-klotho levels and cognitive health}

Women had higher serum $\alpha$-klotho levels of than men $(F[1,93]=9.344, p=0.003$, Fig. 3A $)$. However, there were no sex differences in CSF $\alpha$ klotho levels $(F[1,93]=2.579, p=0.112$, Fig. 3B). Women had lower clinical dementia ratings than men $(F[1,92]=4.253, p=0.042$, Fig. $3 C)$, and nonsignificatly higher average MMSE scores than men $(F[1,92]=3.163, p=0.079$, Fig. 3D $)$. Average age at time of study was similar between the sexes, with an average age of 64.86 years for women, and 66.19 years for men.

\section{Relationship between levels of $\alpha$-klotho and APOE genotype or age}

There was no association between age and levels of $\alpha$-klotho in either the serum $(\mathrm{r}(91)=0.060, p=0.566)$ or the $\operatorname{CSF}(\mathrm{r}(91)=0.073, p=0.490)$. This pattern was seen in both males (Fig. 4A) and females (Fig. 4B). There was also no relationship between age and $\alpha$ klotho levels in any APOE genotype (Fig. 4C, D). A histogram of participant ages is illustrated in Fig. 4E. Additionally, levels of $\alpha$-klotho did not differ across $A P O E$ genotypes in either the serum or the CSF.

\section{No relationship between apoE levels and levels of $\alpha$-klotho, or cognitive health}

There was no relationship between apoE and $\alpha$ klotho levels in either the serum (Fig. 5A) or the CSF (Fig. 5B). There was also no relationship between the levels of apoE in either serum or CSF and MMSE scores or clinical dementia ratings. However, there
A

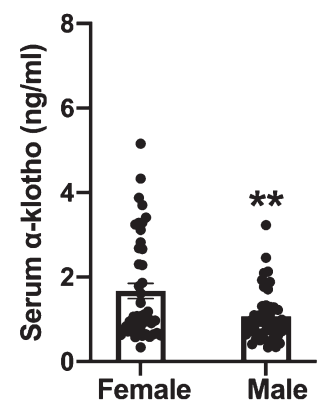

C

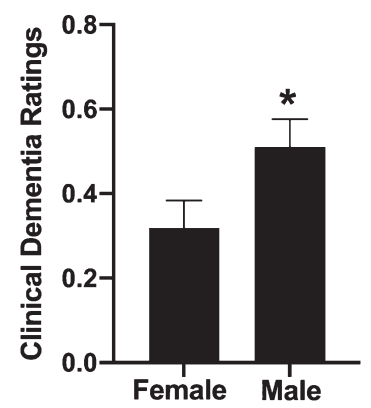

D

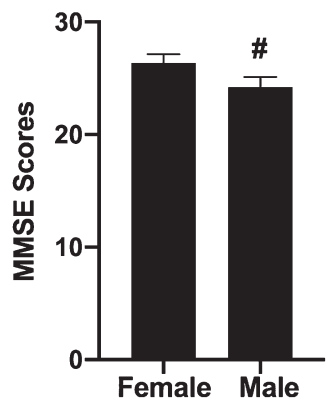

Fig. 3. Women had higher levels of serum $\alpha$-klotho levels than men $* * p=0.003$ (A). However, there were no sex differences in CSF $\alpha$ klotho levels (B). Women had lower clinical dementia ratings than men, $* p=0.043(\mathrm{C})$. and trended towards having higher average MMSE scores than men (D).

was a trend towards a positive association between CSF apoE levels and MMSE scores $(r(89)=0.192$, $p=0.069$ ) (Fig. 5C). There was also a suggestive relationship between $A P O E$ genotype and clinical dementia ratings (Fig. 5D). APOE genotypes are listed from left to right in order of least risk to most risk of developing AD. A stairstep pattern is seen in clinical dementia rating, though an ANOVA revealed no significant differences between groups. In a separate analysis, apoE4 carriers and non-carriers were compared via 2 -tailed $t$-test on clinical dementia ratings, which also yielded no significant difference.

We also investigated whether carriers of different $A P O E$ genotypes had different apoE levels in serum or CSF. Given the small number of apoE2 carriers in our data set, we first conducted an ANOVA to compare apoE3 and apoE4 homozygous and heterozygous carriers by excluding the E2/E3 and E2/E4 carriers. E3/E3 carriers had higher serum apoE levels than $\mathrm{E} 4 / \mathrm{E} 4$ carriers $(F[2,73]=3.512, p=0.035$, Fig. 5E), but there was no genotype difference in CSF apoE levels. 

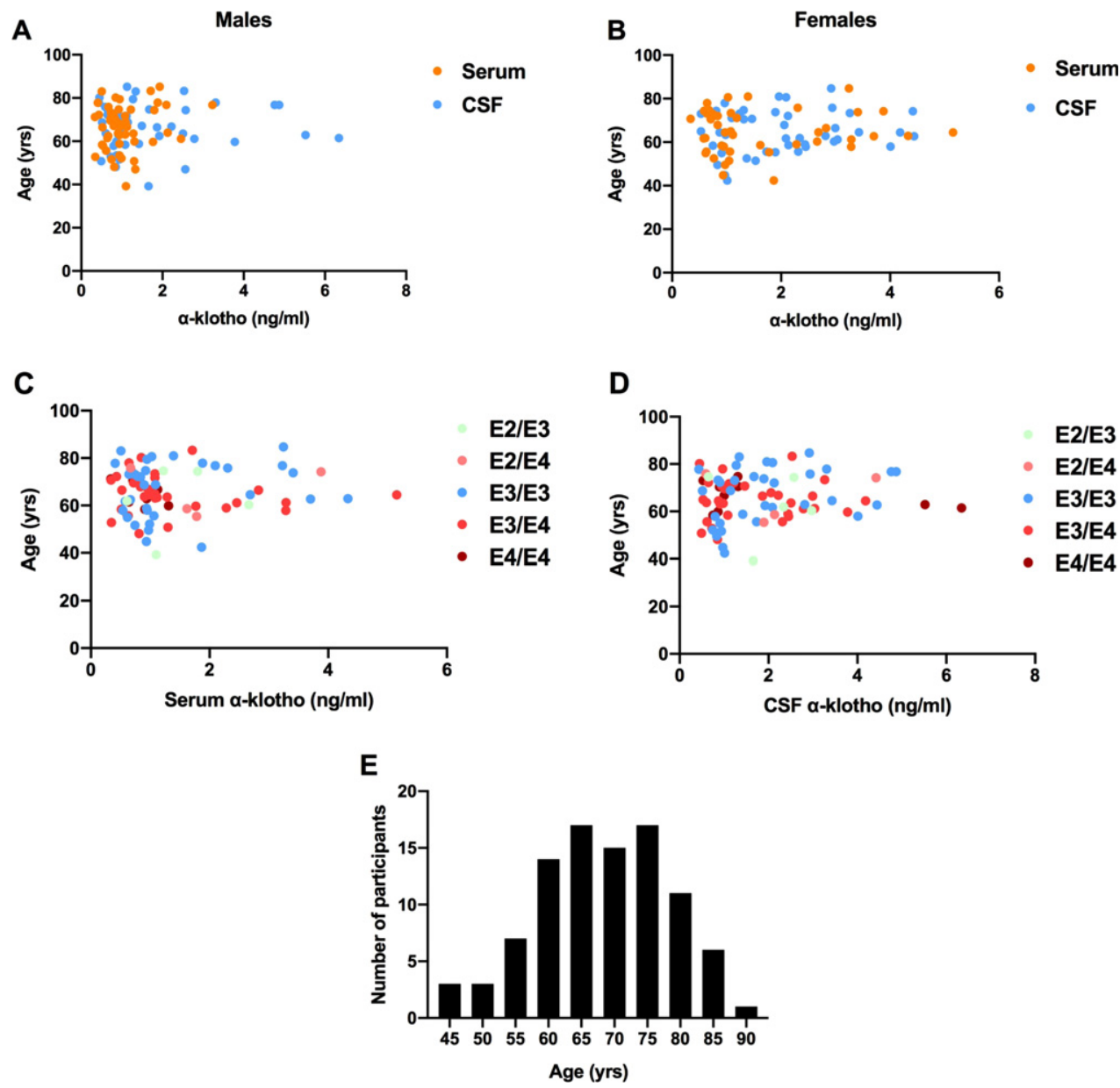

Fig. 4. There was no association between age and $\alpha$-klotho levels in serum or CSF in males (A) or females (B). There was also no relationship between age and $\alpha$-klotho levels in serum (C) or CSF (D) in any APOE genotype. A histogram of participant ages is illustrated in panel E.

We next compared apoE4 carriers and apoE4 noncarriers. ApoE4 carriers had lower serum apoE levels than non-carriers $(F[1,83]=7.590, p=0.007)$. There was no difference in CSF apoE levels between apoE4 carriers and non-carriers. In a comparison between apoE2 carriers vs. non-carriers, there were no differences in serum or CSF levels of apoE. However, we were limited by only having nine apoE2 carriers in our data set.

Finally, we investigated whether the relationship between $A P O E$ genotype and apoE serum or CSF levels was affected by cognitive status. We separately analyzed participants with a clinical dementia rating of 0 from those with a non-zero rating, including all $A P O E$ genotypes. In participants with a clinical dementia rating of zero (40 participants), there was no relationship between serum apoE levels and $A P O E$ genotype. However, in participants with non-zero ratings (44 participants), there was a significant rela- tionship $(F[3,40]=4.152, p=0.012)$. E2/E3 carriers had higher serum apoE levels than E3/E4 $(p=0.046)$ and E4/E4 ( $p=0.033)$ carriers (Fig. 5F). There was no relationship between APOE genotype and CSF apoE levels in either of the cognitive status groups.

\section{$\alpha$-klotho VS (KL-VS) haplotype}

Of the 94 total participants, data about the $\alpha$-klotho VS (KL-VS) haplotype was present for 52 participants. Of those 52 participants, 44 carried no copies of the KL-VS haplotype, 7 carried one copy, and only one participant carried two copies. Due to a very limited number of KL-VS carriers in our sample, we could not confirm the previously reported finding that serum $\alpha$-klotho levels are highest in those carrying one copy of the KL-VS. However, we found that both serum and CSF klotho levels vary robustly within those carrying no copies or one copy of the KL-VS 
A

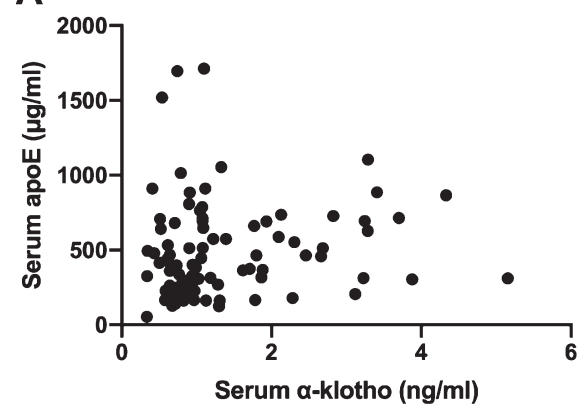

C

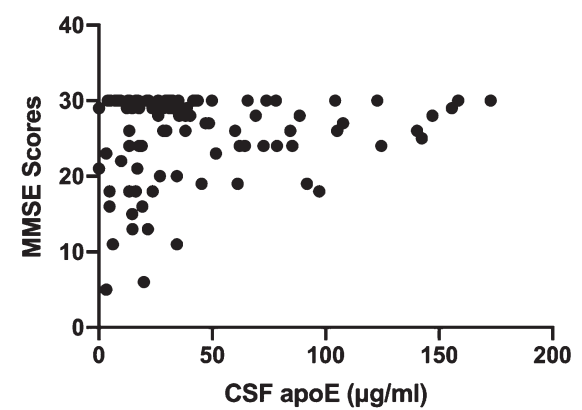

E

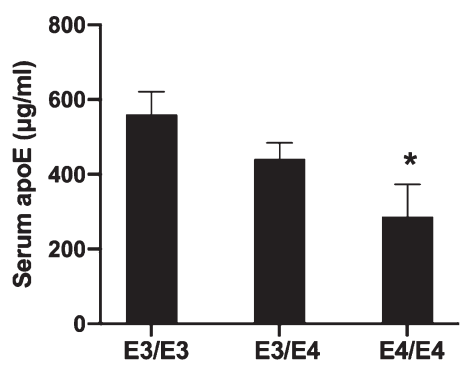

B

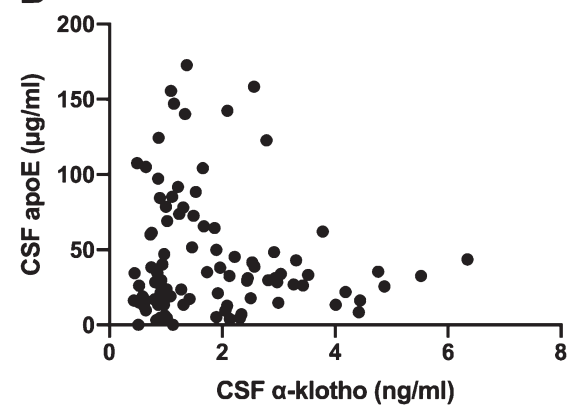

D

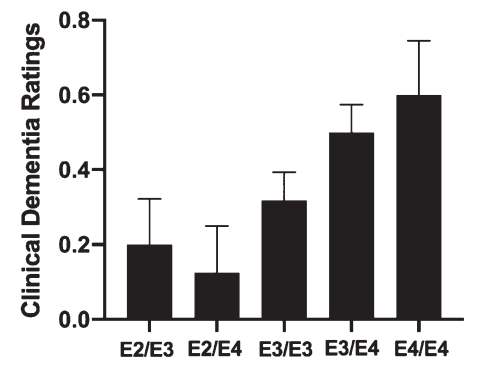

F

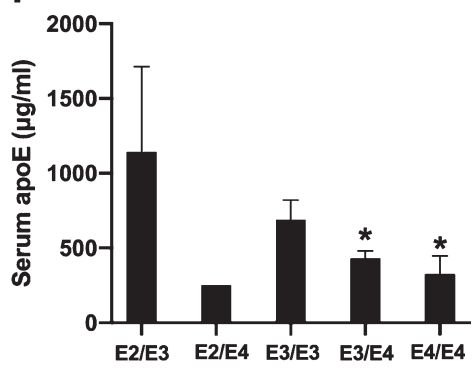

Fig. 5. For all variables with the same letter, the difference between the means is not statistically significant. There was no relationship between apoE and $\alpha$-klotho levels in serum (A) or the CSF (B). There was a trend towards a positive association between CSF apoE levels and MMSE scores (C). There was a suggestive relationship between APOE genotype and clinical dementia ratings, with a stairstep pattern seen in clinical dementia ratings with increasing genetic risk of $\mathrm{AD}$ (D). E3/E3 carriers had higher serum apoE levels than E4/E4 carriers (E). ${ }^{*} p<0.05$ versus E3/E3. In participants with non-zero clinical dementia ratings, E2/E3 carriers had higher serum apoE levels than E3/E4 $(p=0.046)$ and $\mathrm{E} 4 / \mathrm{E} 4$ carriers $(p=0.033)(\mathrm{F}) . * p<0.05$ versus E2/E3.

haplotype. Serum values ranged from $0.34 \mathrm{ng} / \mathrm{ml}$ to $4.33 \mathrm{ng} / \mathrm{ml}$ in those carrying no copies of the KLVS haplotype. In the seven participants carrying one copy of the KL-VS haplotype, serum values of $\alpha$ klotho ranged from $0.34 \mathrm{ng} / \mathrm{ml}$ to $1.88 \mathrm{ng} / \mathrm{ml}$. In our sample, albeit limited in heterozygote KL-VS carriers, the distributions in $\alpha$-klotho levels in serum completely overlap. A 2-tailed $t$-test revealed no significant difference in serum or CSF $\alpha$-klotho levels between those carrying 0 or 1 copies of the KL-VS haplotype. This finding highlights the importance of measuring $\alpha$-klotho levels directly rather than relying on KL-VS haplotype status only.

\section{DISCUSSION}

The $\alpha$-klotho levels we observed in the present study in the serum and CSF of human participants were similar to those reported previously $[3,6,11$, 22]. The $\alpha$-klotho levels in the CSF and serum were highly correlated, indicating that serum $\alpha$-klotho levels may be sufficient to infer CSF $\alpha$-klotho levels 
when CSF is not available or is too invasive to collect. Higher $\alpha$-klotho levels in the CSF and serum were associated with cognitive benefits for all APOE genotypes, not just apoE4 carriers. This result is consistent with a previous study that showed a benefit of high $\alpha$-klotho levels on cognitive outcomes regardless of apoE4 status [3, 6]. However, other studies showed only a benefit for apoE4 carriers [16]. There was an association between higher $\alpha$-klotho levels and higher scores on the MMSE as well as lower CDR. This result is consistent with a previous study showing that higher CSF $\alpha$-klotho levels are associated with higher MMSE scores both in cognitively healthy older adults and adults with AD [3]. However, there was a large amount of variability in both cognitive measures for a given $\alpha$-klotho level. For example, participants carrying apoE4 with CSF $\alpha$ klotho levels less than $1 \mathrm{ng} / \mathrm{ml}$ had MMSE scores ranging from 6 to 29. This indicates that there are large sources of $\alpha$-klotho-independent variability in MMSE scores in apoE4-carrying individuals. This variance could affect whether a greater benefit of high $\alpha$-klotho levels is seen in apoE4 carriers compared to non-carriers in a given study. A recent review of older adults indicated not only differential benefit of $\alpha$-klotho in apoE4 carriers vs. non-carriers, but also that the age at which $\alpha$-klotho levels begin to provide cognitive benefit in apoE4 carriers is around 77 [16]. That result was not found in the present study. At all ages, individuals in the top half of CSF $\alpha$-klotho levels had higher MMSE scores than those in the bottom half, both in apoE4 carriers and non-carriers. Thus, within the age range of the current study, higher $\alpha$ klotho levels are associated with cognitive benefit at all ages and that this benefit is not limited to being an apoE4 carrier.

Women had better cognitive health than men in the present study, with significantly lower clinical dementia ratings and marginally higher scores on the MMSE. This result is consistent with previous studies suggesting a greater resilience to age-related cognitive decline in women than men on many cognitive measures in cognitively healthy adults [23]. Remarkably, women had higher serum, but not CSF, levels of $\alpha$-klotho than men, suggesting that the higher serum $\alpha$-klotho levels in women might contribute to their greater resilience. In contrast to the results of the current study, women had lower $\alpha$-klotho CSF levels than men in a previous study [3], and in another study, there were no sex differences in serum $\alpha$-klotho levels [22]. Individual variability in soluble $\alpha$-klotho levels is large. Therefore, the inconsistent sex differences in
CSF and serum $\alpha$-klotho levels across studies might be due to the large individual variability in these measures and other genetic or environmental factors. For example, women are at greater risk for developing $\mathrm{AD}$ than men and suffer greater cognitive decline than men at the same stage of the disease [24]. Sex differences in cognitive trajectories might depend on a variety of factors, including whether the individual is undergoing healthy or pathological age-related cognitive decline.

Contrary to previous findings, we did not find a decline in serum or CSF $\alpha$-klotho levels with age [3, 25]. This might be due to the distribution of ages in the present study. $\alpha$-klotho levels are highest in children and begin to decline in middle age, though with large inter-individual variability [22]. The mean age of our sample was 66 . Therefore, an age-related decline in $\alpha$-klotho levels might have been observed if the sample contained more individuals at younger ages.

We found no differences in serum or CSF $\alpha$-klotho levels across APOE genotypes or between apoE4 carriers versus non-carriers. We also found no association between protein levels of apoE and $\alpha$-klotho in either serum or CSF. To the best of our knowledge, we are the first to investigate this question by measuring $\alpha$-klotho levels directly rather than using KL-VS haplotype as a proxy for $\alpha$-klotho protein levels. Some previous research showed that $\alpha$-klotho, $\mathrm{A} \beta$ burden, and apoE4-driven cognitive decline do not interact significantly [26], though the literature on this is mixed [16].

The mechanisms by which $\alpha$-klotho offers cognitive benefit are not fully clear. Addition of klotho to neurons is beneficial via an anti oxidative mechanism [27]; Klotho enhanced the expression of the thioredoxin/peroxiredoxin (Trx/Prx) system, especially of Prx-2, an antioxidant enzyme. Klotho-induced phosphorylation of the PI3K/Akt pathway, a pathway important in apoptosis and longevity, was associated with sustained inhibitory phosphorylation of the transcription factor forkhead box O3a (FoxO3a) and essential for the induction of Prx-2. Klotho can also induce the differentiation of oligodendrocyte progenitor to mature oligos [28] and was shown to be neuroprotective and anti inflammatory in an amyotrophic lateral sclerosis mouse model [29].

Low serum $\alpha$-klotho levels are an independent predictor of all-cause mortality in older adults, indicating it may have a role in overall health [30]. $\alpha$-klotho also seems to have direct effects within the brain. In transgenic mice that overexpress $\alpha$-klotho, total 
protein levels of the NMDAR subunit GluN2B are increased through post-transcriptional mechanisms [6]. This increase is associated with an improvement in spatial learning and memory in the Morris water maze [6].

There was no correlation between protein levels of apoE in the serum and CSF. Protein levels of apoE in the serum or CSF did not significantly correlate with MMSE scores or clinical dementia ratings. However, there was a trend towards a positive association between CSF apoE levels and MMSE scores. Whether higher apoE levels in the serum or CSF are associated with healthier brain outcomes is still being elucidated. In some studies, higher CSF levels of apoE are associated with neurodegeneration [31-35], while in other studies, the opposite pattern is seen [36-38]. In one study, higher CSF apoE levels were beneficial in apoE4 non-carriers, but the opposite pattern was seen in apoE4 carriers [39].

The serum levels of apoE were higher in E3/E3 than E4/E4 carriers, but there was no difference in the CSF apoE levels between these two genotypes. Similarly, apoE4 carriers had lower serum apoE levels than non-carriers, but there were no differences in CSF apoE levels. Some studies showed that carrying apoE3 is associated with higher serum and CSF levels of apoE than carrying apoE4 in both cognitively healthy controls and those with $\mathrm{AD}[40,41]$. The APOE genotype was found to explain $24 \%$ of the variability in plasma apoE levels and $12 \%$ of the variability in CSF apoE levels [40]. Our data partially support this finding, showing a relationship in serum, but not CSF, levels of apoE with $A P O E$ genotype. A larger sample size might have revealed a small effect of $A P O E$ genotype on CSF apoE levels. When we included all available $A P O E$ genotypes in our data, including the small number of apoE2 carriers, serum apoE levels were related to $A P O E$ genotype in participants with a non-zero clinical dementia rating, but not in cognitively healthy participants. In participnts with non-zero clinical dementia ratings, E2/E3 carriers had higher serum apoE levels than E3/E4 and $\mathrm{E} 4 / \mathrm{E} 4$. This indicates that cognitive status may be an important factor for the relationship between apoE levels, $A P O E$ genotype, and brain health.

One significant strength of the present study is that we measured $\alpha$-klotho levels directly instead of inferring them based on haplotypes. Our results indicate that KL-VS haplotype may not be an adequate proxy measurement for $\alpha$-klotho levels in serum or CSF, given the large variability in $\alpha$-klotho levels within each haplotype group. Recent studies showing no association between KL-VS status and cognitive health in older adults might be explained by the highly variable levels of $\alpha$-klotho within a haplotype group [42]. Limitations in the present study include the ceiling effects in the MMSE scores of some study participants, the relative low number of E4/E4 study participants, and a survival bias.

In conclusion, serum and CSF $\alpha$-klotho levels are highly correlated. Both are strongly associated with higher MMSE scores and lower clinical dementia ratings, supporting a protective cognitive role for $\alpha$ klotho and allowing inference of CSF levels from serum levels in future studies. Women showed higher serum $\alpha$-klotho levels than males. Within the age range studied, $\alpha$-klotho levels did not decline. Finally, apoE levels did not correlate with $\alpha$-klotho levels in serum or CSF. Still, there was a trend towards a positive association between CSF apoE levels and MMSE scores, indicating a possible protective role of higher $\mathrm{CSF}$ apoE protein levels. Future studies are warranted involving a wider range of participant ages to more fully investigate serum and CSF changes in $\alpha$-klotho levels over the lifespan.

\section{ACKNOWLEDGMENTS}

We thank Dr. Carmela Abraham for valuable advice regarding the $\alpha$-klotho analyses.

The current study was partially supported by NIA T32 AG055378 (PK), a Beckman Postdoctoral Fellowship with funding provided by the Arnold and Mabel Beckman Foundation, and a Burroughs Welcome Fund Collaborative Research Travel Grant (1018797) (BZ), NIH RF1 AG059088, R21 AG065914 (JR), and a grant to the OHSU Alzheimer's Disease Research Center (NIH P30AG066518; P30-AG008017) (JK).

Authors' disclosures available online (https:// www.j-alz.com/manuscript-disclosures/21-5719r1).

\section{SUPPLEMENTARY MATERIAL}

The supplementary material is available in the electronic version of this article: https://dx.doi.org/ 10.3233/JAD-215719.

\section{REFERENCES}

[1] Kuro-o M (2019) The Klotho proteins in health and disease. Nat Rev Nephrol 15, 27-44.

[2] Dolegowska K, Marchelek-Mysliwiec M, NowosiadMagda M, Slawinski M, Dolegowska B (2019) FGF19 
subfamily members: FGF19 and FGF21. J Physiol Biochem 75, 229-240.

[3] Semba RD, Moghekar AR, Hu J, Sun K, Turner R, Ferucci L, O'Brien R (2014) Klotho in the cerebrospinal fluid of adults with and without Alzheimer's disease. Neurosci Lett $\mathbf{5 5 8}, 37-40$.

[4] Uchida A, Tashiro KY, Yorifuji H, Kishimoto T, Nabeshima Y, Hisanaga S (2001) Neurofilaments of Klotho, the mutant mouse prematurely displaying symptoms resembling human aging. J Neurosci Res 64, 364-370.

[5] Kurosu H, Yamaoto M, Clark JD, Pastor JV, Nandi A, Gurnani P, McGuinness, OP, Chikuda, H, Yamaguchi M, Kawaguchi H, Shimomura I, Takayama Y, Herz J, Kahn CR, Rosenblatt KP, Kuro-o M (2005) Suppression of aging in mice by the hormone Klotho. Science 309, 1829-1833.

[6] Dubal DB, Zhu L, Sanchez PE, Worden K, Broestl L, Johnson E, Ho K, Yu G-Q, Kim D, Betourne A, Kuro-o M, Masliah E, Abrahamm CR, Mucke L (2014) Life extension factor klotho prevents mortality and enhances cognition in hAPP transgenic mice. J Neurosci 35, 2358-2371.

[7] Shiraki-Iida T, Aizawa H, Matsumura Y, Sekine S, Iida A, Anazawa H, Nagai R, Kuro-o M, Nabeshima Y-I (1998) Structure of the mouse klotho gene and its two transcripts encoding membrane and secreted protein. FEBS Lett 424, 6-10.

[8] Yokoyama JS, Marx G, Brown JA, Bonham LW, Wang D, Coppola G, Seeley WW, Rosen HJ, Miller BL, Kramer JH, Dubal DB (2017) Systemic klotho is associated with KLOTHO variation and predicts intrinsic cortical connectivity in healthy human aging. Brain Imaging Behav 11, 391-400.

[9] Jones NS, Watson KQ, Rebeck GW (2019) Metabolic disturbances of a high-fat diet are dependent on APOE genotype and sex. eNeuro 6, ENEURO.0267-19.2019.

[10] Johnson LA, Torres ERS, Impey S, Stevens JF, Raber J (2017) Apolipoprotein E4 and insulin resistance interact to impair cognition and alter the epigenome and metabolome. Sci Rep 7, 43701.

[11] Yokoyama JS, Sturm VE, Bonham LW, Klein E, Arfanakis K, Yu L, Coppola G, Kramer JH, Bennett DA, Miller BL, Dubal DB (2015) Variation in longevity gene KLOTHO is associated with greater cortical volumes. Ann Clin Translation Neurol 2, 215-230.

[12] Bertrand P, Poirier J, Oda T, Finch CE, Pasinetti GM (1995) Association of apolipoprotein E genotype with brain levels of apolipoprotein $\mathrm{E}$ and apolipoprotein $\mathrm{J}$ (clusterin) in Alzheimer disease. Mol Brain Res 33, 174-178.

[13] Riddell DR, Zhou H, Atchison K, Warwick HK, Atkinson PJ, Jefferson J, Xu L, Aschemies S, Kirksey Y, Hu Y, Wagner E, Parratt A, Xu J, Li Z, Zaleska MM, Jaconsen JS, Pangalos MN, Reinhart PH (2008) Impact of Apolipoprotein E (ApoE) polymorphism on brain ApoE levels. J Neurosci 28, 11445-11453.

[14] Flowers SA, Rebeck GW (2020) APOE in the normal brain. Neurobiol Dis 136, 104724.

[15] Erickson CM, Schultz SA, Oh JM, Darst BF, Ma Y, Norton D, Betthauser T, Gallagher CL, Carlsson CM, Bendlin BB, Ashana S, Hermann BP, Sager MA, Blennow K, Zetterberg H, Engelman CD, Christian BT, Johnson SC, Dubal DB, Okonwo OC (2019) KLOTHO heterozygosity attenuates APOE4-related amyloid burden in preclinical AD. Neurology 92, e1878-e1889.

[16] Belloy ME, Napolioni V, Han SS, Le Guen Y, Greicius MD (2020) Association of Klotho-VS heterozygosity with risk of Alzheimer disease in individuals who carry APOE4. JAMA Neurol 77, 849-862.

[17] Kundu P, Zimmerman B, Perez R, Whitlow CT, Cline JM, Olson JD, Andrews RN Raber J (2021) Apolipoprotein E levels in the amygdala and prefrontal cortex predict relative regional brain volumes in irradiated Rhesus macaques. Sci Rep 11, 22130.

[18] Higuchi Y, Nelson GA, Vazquez M, Laskowitz DT, Slater JM, Pearlstein RD (2002) Apolipoprotein E expression and behavioral toxicity of high charge, high energy (HZE) particle radiation. J Radiat Res $\mathbf{4 3}$ (Suppl), S219-224.

[19] Villasana L, Acevedo S, Poage C, Raber J (2006) Sex- and APOE isoform-dependent effects of radiation on cognitive function. Radiat Res 166, 883-891.

[20] Robertson J, Curley J, Kaye J, Quinn J, Pfankuch T, Raber J (2005) apoE isoforms and measures of anxiety in probable AD patients and Apoe-/- mice. Neurobiol Aging 26, 637643.

[21] O’Bryant SE, Waring SC, Cullum CM, Hall J, Lacritz L, Massman PJ, Lupo PJ, Reisch JS, Doodly R, Texas Alzheimer's Research Consortium (2008) Staging dementia using Clinical Dementia Rating Scale Sum of Boxes scores: A Texas Alzheimer's Research Consortium Study. Archiv Neurol 65, 1091-1095.

[22] Yamazaki Y, Imura A, Urakawa I, Shimada T, Murakami J, Aono Y, Hasegawa H, Yaamashita T, Nakatani K, Saito Y, Okamoto N, Kurumatani N, Namba N, Kitaoka T, Ozono K, Sakai T, Hatay H, Ichikawa S, Imel EA, Econs MJ, Nabeshima Y-I (2010) Establishment of sandwich ELISA for soluble alpha-Klotho measurement: Age-dependent change of soluble alpha-Klotho levels in healthy subjects. Biochem Biophys Res Comm 398, 513-518.

[23] McCarrey AC, An Y, Kitner-Triolo MH, Ferrucci L, Resnick SM (2016) Sex differences in cognitive trajectories in clinically normal older adults. Psychol Aging 31, 166-175.

[24] Laws KR, Irvine K, Gale TM (2018) Sex differences in Alzheimer's disease. Curr Opin Psychiatry 31, 133-139.

[25] Behringer V, Stevens JMG, Deschner T, Sonnweber R, Hohmann G (2018) Aging and sex affect soluble alpha klotho levels in bonobos and chimpanzees. Front Zool 15, 35 .

[26] Porter T, Burnham SC, Milicic L, Savage G, Maruff P, Lim YY, Ames D, Masters CL, Martins RN, Rainey-Smith S, Rowe CC, Salvado O, Groth D, Verdile G, Villemagne VL, Laws SM (2019) Klotho allele status is not associated with $\mathrm{A} \beta$ and APOE $\varepsilon$ 4-related cognitive decline in preclinical Alzheimer's disease. Neurobiol Aging 76, 162-165.

[27] Zeldich E, Chen C-D, Colvin TA, Bove-Fenderson EA, Liang J, Tucker Zhou TB, Harris DA, Abraham CR (2014) The neuroprotective effect of Klotho is mediated via regulation of members of the redox system. J Biol Chem 289, 24700-24715.

[28] Chen C-D, Solane JA, Li H, Aytan N, Giannaris EL, Zeldich E, Hinman JD, Dedeoglu A, Rosene DL, Bansal R, Luebke JI, Kuro-o M, Abraham CR (2013) The antiaging protein klotho enhances oligodendrocyte maturation and myelination of the CNS. J Neurosci 33, 1927-1939.

[29] Zeldich E, Chen C-D, Boden E, Howat B, Nasse JS, Zeldich D, Lambert AG, Yuste A, Cherry JD, Mathias RM, Ma Q, Lau NC, McKee AC, Hatzepiros T, Abraham CR (2019). Klotho is neuroprotective in the Superoxide Dismutase $\left(\mathrm{SOD}^{\mathrm{G} 93 \mathrm{~A}}\right)$ mouse model of ALS. J Mol Neurosci 69 , 264-285.

[30] Semba RD, Cappola AR, Sun K, Bandinelli S, Dalal M, Crasto C, Guralnik JM, Ferrucci L (2011) Plasma klotho 
and mortality risk in older community-dwelling adults. J Gerontol A Biol Sci Med Sci 66, 794-800.

[31] Shafaati M, Solomon A, Kivipelto M, Björkhem I, Leoni V (2007) Levels of ApoE in cerebrospinal fluid are correlated with Tau and 24S-hydroxycholesterol in patients with cognitive disorders. Neurosci Lett 425, 78-82.

[32] Fukuyama R, Mizuno T, Mori S, Yanagisawa K, Nakajima K, Fushiki S (2000) Age-dependent decline in the apolipoprotein $\mathrm{E}$ level in cerebrospinal fluid from control subjects and its increase in cerebrospinal fluid from patients with Alzheimer's disease. Eur Neurol 43, 161-169.

[33] Lindh M, Blomberg M, Jensen M, Basun H, Lannfelt L, Engvall B, Scharnagel H, Marz W, Wahlund LO, Cowburn RF (1997) Cerebrospinal fluid apolipoprotein E (apoE) levels in Alzheimer's disease patients are increased at follow up and show a correlation with levels of tau protein. Neurosci Lett 229, 85-88.

[34] Merched A, Blain H, Visvikis S, Herbeth B, Jeandel C, Siest G (1997) Cerebrospinal fluid apolipoprotein E level is increased in late-onset Alzheimer's disease. J Neurol Sci 145, 33-39.

[35] Slot RER, Van Harten AC, Kester MI, Jongbloed W, Bouwman FH, Teunissen CE, Scheltens P, Veerhuis R, van der Flier WM (2017) Apolipoprotein A1 in cerebrospinal fluid and plasma and progression to Alzheimer's disease in nondemented elderly. J Alzheimers Dis 56, 687-697.

[36] Blennow K, Hesse C, Fredman P (1994) Cerebrospinal fluid apolipoprotein E is reduced in Alzheimer's disease. $\mathrm{Neu}$ roreport 5, 2534-2536.
[37] Hesse C, Larsson H, Fredman P, Minthon L, Andreassen N, Davidsson P, Blennow K (2000) Measurement of apolipoprotein E (apoE) in cerebrospinal fluid. Neurochem Res 25, 511-517.

[38] Landén M, Hesse C, Fredman P, Regland B, Wallin A, Blennow K (1996) Apolipoprotein E in cerebrospinal fluid from patients with Alzheimer's disease and other forms of dementia is reduced but without any correlation to the apoE4 isoform. Dementia 7, 273-278.

[39] Andres MA, Feger U, Nath A, Munsaka S, Jiang CS, Chang L (2011) APOE $\varepsilon 4$ allele and CSF APOE on cognition in HIV-infected subjects. J Neuroimmune Pharmacol 6, 389398.

[40] Cruchaga C, Kauwe JS, Nowotny P, Bales K, Pickering EH, Mayo K, Bertelsen S, Hinrichs A; Alzheimer's Disease Neuroimaging Initiative, Fagan AM, Holtzman DM, Morris JC, Goate AM (2012) Cerebrospinal fluid APOE levels: An endophenotype for genetic studies for Alzheimer's disease. Hum Mol Genet 21, 4558-4571.

[41] Lehtimäki T, Pirrtila T, Mehta PD, Wisniewsky HM, Frey H, Nikkari T (1995) Apolipoprotein E (apoE) polymorphism and its influence on ApoE concentrations in the cerebrospinal fluid in Finnish patients with Alzheimer's disease. Hum Genet 95, 39-42.

[42] Müller BW, Hinney A, Scherbaum N, Weimar C. (2021) Klotho KL-VS haplotype does not improve cognition in a population-based sample of adults age 55-87 years. Sci Rep 11, 13852. 